\title{
The effect of choice reversals on blindness for identification decisions
}

Citation for published version (APA):

Sagana, A., Sauerland, M., \& Merckelbach, H. (2016). The effect of choice reversals on blindness for identification decisions. Psychology Crime \& Law, 22(4), 303-314.

https://doi.org/10.1080/1068316X.2015.1085984

Document status and date:

Published: 20/04/2016

DOI:

10.1080/1068316X.2015.1085984

Document Version:

Publisher's PDF, also known as Version of record

Document license:

Taverne

Please check the document version of this publication:

- A submitted manuscript is the version of the article upon submission and before peer-review. There can be important differences between the submitted version and the official published version of record.

People interested in the research are advised to contact the author for the final version of the publication, or visit the DOI to the publisher's website.

- The final author version and the galley proof are versions of the publication after peer review.

- The final published version features the final layout of the paper including the volume, issue and page numbers.

Link to publication

\footnotetext{
General rights rights.

- You may freely distribute the URL identifying the publication in the public portal. please follow below link for the End User Agreement:

www.umlib.nl/taverne-license

Take down policy

If you believe that this document breaches copyright please contact us at:

repository@maastrichtuniversity.nl

providing details and we will investigate your claim.
}

Copyright and moral rights for the publications made accessible in the public portal are retained by the authors and/or other copyright owners and it is a condition of accessing publications that users recognise and abide by the legal requirements associated with these

- Users may download and print one copy of any publication from the public portal for the purpose of private study or research.

- You may not further distribute the material or use it for any profit-making activity or commercial gain

If the publication is distributed under the terms of Article $25 \mathrm{fa}$ of the Dutch Copyright Act, indicated by the "Taverne" license above, 


\section{The effect of choice reversals on blindness for identification decisions}

\section{Anna Sagana, Melanie Sauerland \& Harald Merckelbach}

To cite this article: Anna Sagana, Melanie Sauerland \& Harald Merckelbach (2016) The effect of choice reversals on blindness for identification decisions, Psychology, Crime \& Law, 22:4, 303-314, DOI: 10.1080/1068316X.2015.1085984

To link to this article: https://doi.org/10.1080/1068316X.2015.1085984

\section{Published online: 07 Oct 2015.}

Submit your article to this journal $\sqsubset$

山ll Article views: 369

Q View related articles ๘

View Crossmark data $₫$

Citing articles: 2 View citing articles ๘ 


\title{
The effect of choice reversals on blindness for identification decisions
}

\author{
Anna Sagana, Melanie Sauerland and Harald Merckelbach \\ Forensic Psychology Section, Department of Clinical Psychological Science, Faculty of Psychology and \\ Neuroscience, Maastricht University, Maastricht, The Netherlands
}

\begin{abstract}
The present study examined blindness for identification decisions from target-present (TP) and target-absent (TA) lineups using a field study methodology. Eighty pedestrians were exposed to a staged theft. Subsequently, they were asked to identify the thief and the victim from separate, simultaneous six-person lineups. Their identification decision concerning the thief lineup was manipulated such that participants' selections were exchanged with a previously unidentified lineup member (choice exchange) and lineup rejections were turned into identifications (choice reversal). Participants were 7-10 times less likely to detect choice exchanges (66.7\%) compared with choice reversals (11.2\%). Furthermore, identification accuracy was not a prerequisite for detection. Thus, rejections and particularly selections made from both TP and TA lineups are susceptible to choice blindness. Finally, our study implies that for blindness in eyewitness identification decisions between-category changes (i.e. choice reversals) are easier to detect than within-category changes (i.e. choice exchanges).
\end{abstract}

\section{ARTICLE HISTORY}

Received 25 February 2015

Accepted 30 July 2015

\section{KEYWORDS}

Blindness phenomena; eyewitness identification; selection vs. rejection; identification accuracy; decision-making

\section{Introduction}

At first glance, the case of B. Maughan (Wolchover, n.d.) looks like a typical police lineup procedure: A witness identified lineup member six from a live lineup in the presence of a solicitor. Subsequently, the lineup administrator wrote down and read back the identification statement to the witness and B. Maughan was charged with involvement in a road rage attack. What the lawyer who reviewed the identification tapes on appeal found, though, took him by surprise. The lineup administrator had written down a different lineup member than the one identified by the witness. Although the administrator repeated aloud the wrong lineup number, both the witness and the solicitor failed to detect the mistake. This, then, signals a real live instance of an altered lineup decision that remained unnoticed (for details, see Sagana, Sauerland, \& Merckelbach, 2014b). Although anecdotal, the Maughan case raises the question to what extent and under what conditions the outcome of eyewitness identification decisions can be corrupted by this type of error. 
Recent research on the effect of choice blindness suggests that people can be oblivious to secret changes in the outcome of their decisions (Johansson, Hall, Sikström, \& Olsson, 2005). In a typical choice blindness task after indicating a choice or preference, participants are presented with either their original response or with a response that is inconsistent with their primary decision, and they are asked to explain the reason for that choice. The typical finding is that in their great majority participants remain unaware of the change in the outcome of their decision. The basic choice blindness paradigm has been extended into various sensory modalities (e.g. Johansson, Hall, \& Sikström, 2008; Sauerland, Sagana, \& Otgaar, 2013; Steenfeldt-Kristensen \& Thornton, 2013) and contexts including consumer preferences (Hall, Johansson, Tärning, Sikström, \& Deutgen, 2010), financial decisions (McLaughlin \& Somerville, 2013), symptom reporting (Merckelbach, Jelicic, \& Pieters, 2011a, 2011b), moral decision-making (Hall, Johansson, \& Strandberg, 2012) and autobiographical memory (Sauerland, Schell, et al., 2013; Sauerland, Schell-Leugers, \& Sagana, 2015).

Applying the choice blindness paradigm in the case of lineup decision manipulations, Sagana, Sauerland, and Merckelbach $(2013,2014 b)$ found that almost $40 \%$ of the witnesses failed to notice the change. Specifically, Sagana et al. (2013) engaged pedestrians in a conversation with two experimenters who pretended to be tourists. Subsequently, pedestrians had to identify these two tourists from simultaneous, six-person photo lineups, using a forced-choice recognition format. Having provided a description of the witnessed event, participants were presented with their lineup decisions and were asked to explain the reasons behind their choices. However, their selection for the second target was exchanged with another previously non-selected lineup member. Most participants (69\%) failed to detect the identity manipulation when confronted with it (i.e. concurrent blindness). Furthermore, participants who had been accurate in their recognition decision from the outset were more likely to detect the manipulation than those who had been inaccurate. To address the possibility that participants had noticed the change but refrained from revealing it, participants were informed about the chance of a manipulation at the end of the experiment. Even then the blindness rate was still $40 \%$ (i.e. retrospective blindness). Moreover, earlier research suggests that compliance (Johansson et al., 2005, 2008; Sauerland, Sagana, et al., 2013), suggestibility (Merckelbach et al., 2011a; Sauerland, Schell, et al., 2013) or the tendency to react in socially desirable ways (Merckelbach et al., 2011a; Sauerland, Sagana, et al., 2013) do not moderate blindness.

Following that dramatic display of blindness for recognition decisions, Sagana et al. (2014b) aimed to determine the border conditions of blindness for recognition decisions. In the controlled environment of the laboratory and when the manipulated outcome was presented immediately after the selection (Experiments $2(\mathrm{a}-\mathrm{c})$, blindness for recognition decisions was comparably low (concurrent: $25-33 \%$, retrospective: $0-6 \%$ ). When a 48-h interval between the recognition decision and the presentation of the manipulated outcome was inserted (Experiment 3), concurrent (68\%) and retrospective (39\%) blindness rates approached the levels reported in the field study. However, unlike the findings in the field study (Sagana et al., 2013), identification accuracy did not predict neither concurrent nor retrospective detection rates. Thus, the authors suggested that memory strength, which is an important determinant of identification performance, is insufficient to explain blindness phenomena. Further support for this position comes from the finding that 
participants are capable of remembering their choices with precision when asked to do so, despite being blind to manipulations (Sagana, Sauerland, \& Merckelbach, 2014a). Another finding to consider is that blindness phenomena can occur minutes after the original choice (Hall et al., 2010; Johansson et al., 2005) as well as for decisions of personal relevance (Hall et al., 2012; Sauerland, Sagana, Otgaar, \& Broers, 2014) and for autobiographical reports (Sauerland, Schell, et al., 2013), where one expects memory to be strong.

The work by Sagana et al. $(2013,2014 b)$ was an essential first step in showing that blindness may have far-reaching implications for the legal domain. As the ambition of these pioneer studies was to provide an existing proof of blindness in typical eyewitness settings, the complexity of the experimental designs was restricted to keep the impact of confounders at a minimum. Specifically, these studies exclusively relied on target-present (TP) lineups and a forced-choice format. However, the innocence or guilt status of the suspect is unknown in real cases, and every administered lineup may potentially be a target-absent (TA) lineup. In a TA lineup, a covert manipulation, where a foil identification would be turned into a suspect identification, could lead to the imprisonment of an innocent suspect on false premises. Furthermore, in real cases, eyewitnesses should be warned that the perpetrator may or may not be present in the lineup (Wells et al., 1998) and witnesses should be given the option to reject the lineup (i.e. nonchoosers). Accordingly, the question arises whether turning a lineup rejection into a positive identification (i.e. choice reversal) would elicit lower blindness rates than an exchange of lineup members (i.e. choice exchange). In the present study, we addressed this issue by examining blindness phenomena under conditions that are comparable to real lineup identification decisions.

Employing a field study methodology similar to the one used by Sagana et al. (2013), the current study aims to replicate previous findings on blindness for identification decisions and to expand our understanding of these errors by (a) presenting TA and TP lineups and (b) providing the option to reject the lineup. This enabled us to manipulate both choosers' and nonchoosers' decisions. Specifically, nonchoosers' rejections were turned into identifications and choosers' identification decisions were exchanged (i.e. swapped with a different lineup member). We refrained from turning lineup identifications into rejections because they are of little relevance to the legal system, as there is only a small if any incentive for this type of conversion (although we acknowledge the possibility of an honest mistake). Finally, to further increase the ecological validity and the generalizability of our findings, a live mock crime was employed. All participants were individually exposed to the live theft of a backpack. Although a staged crime cannot mimic a real crime scene for ethical reasons, it can introduce the element of surprise and thus simulate realistic encoding conditions. Therefore, field experiments can differentiate our understanding of the mechanisms involved in eyewitness identification (Cutler \& Penrod, 1995). The present field experiment provides insight into the readiness of eyewitnesses to detect changes in their identifications, for an event that occurred under conditions of divided attention which resemble real life. We therefore consider the field methodology a valuable research approach.

We assume that the mismatch between participants' decision and the manipulated outcome would be greater for nonchoosers than for choosers. We base this assumption on the belief that a selection implies a match between the memory of the culprit and one of the lineup members, while a rejection reflects a reluctance to identify any of the faces in the lineup as the culprit (Sporer, Penrod, Read, \& Cutler, 1995; Weber \& Brewer, 2006). Thus, when presented with the manipulated outcome, for choosers the comparison 
would rest on the specific facial characteristic of the identified suspect ('Did I identify this person or another person?'), while for nonchoosers the comparison would rest on a higher and less ambiguous decision level ('Did or did I not make an identification?'). In other words, the manipulation constitutes a within-category change for choosers but a between-category change for nonchoosers. Accordingly, we hypothesize that nonchoosers would be more resistant to manipulations than choosers. In line with this assumption is also research on the related phenomenon of change blindness, which refers to the inability to detect visual changes if these are combined with visual disturbance (e.g. eye-movement, blink, distracting stimuli). For example, presented with intact and scrambled versions of schematic faces, participants were more likely to detect a change when intact and scrambled faces were interchanged (between-category) than when a scrambled or intact face was changed into another scrambled or intact face (Lyyra, Mäkelä, Hietanen, \& Astikainen, 2014). These results indicate that between-category changes are more easily detected than within-category changes. Moreover, assuming that rejections occur more often for TA than for TP lineups, we expect blindness rates to be higher for TP compared with TA lineups. Finally, based on earlier findings suggesting that even people who are accurate in their identification decision are susceptible to blindness manipulations (Sagana et al., 2013), we expect identification accuracy to be unrelated to blindness levels in both choosers and nonchoosers.

\section{Method}

\section{Participants}

Eighty participants (19 male, $M_{\text {age }}=21.6, \mathrm{SD}_{\text {age }}=4.7$, age range $18-49$ ), who were mostly bachelor (58.9\%) and master (31.3\%) students on their way to enter a university building, took part in this study. The educational level of eight participants (10.0\%) is missing because, in order for the thief to remain visible equally long among participants, the play of the crime scene interfered with the collection of the demographics. All participants were tested individually on a voluntary basis and no incentives were granted. The study was approved by the standing ethical committee of the faculty.

\section{Material}

\section{Lineups}

Three TA and three TP simultaneous photo lineups were created. The target persons were three psychology students (one female, age range: 22-25 years). Head and shoulder photos were selected to fit the description of the respective targets (effective sizes determined as Tredoux's E-values ranged from 4.13 to 5.00; Tredoux, 1998, 1999). Lineups consisted of six $7.0 \times 6.0 \mathrm{~cm}$ frontal face, head and shoulder photos, presented in three pictures a row, on a $29.7 \times 21.0 \mathrm{~cm}$ laminated display board. Each lineup included one target (i.e. perpetrator or victim) or replacement of the target and five foils. On the right side of the board, next to the six photos, a rejection option was provided.

\section{Post-test questionnaire}

To examine whether participants noticed our manipulation, yet refrained from mentioning it, we administered a post-test questionnaire (adjusted from Johansson et al., 2008). 
Participants were first asked whether they encountered any problems during the experiment and what the nature of these problems was. Subsequently, they were falsely informed that the study employed two conditions: one in which their identification decisions had been changed (experimental condition) and another where their decisions had remained intact (control condition). Participants were invited to indicate in which condition they thought they had participated. If participants responded that they had been assigned to the experimental condition, they had to indicate how many times and for which target(s) they had noticed a manipulation. These answers, if correct, were counted as retrospective detection.

\section{Design}

A 2 (manipulation status: manipulated vs. non-manipulated lineups) $\times 2$ (lineup mode: TA vs. TP) within-subjects design was employed. To avoid recognition effects caused by differences in distinctiveness and anchoring, we counterbalanced (a) which of the two male experimenters ${ }^{1}$ acted as the victim or the actual experimenter, and (b) the sequence of TA and TP lineup mode across perpetrator and victim lineups (i.e. TA-TP, TA-TA, TP-TA and TP-TP). Detection rates did not vary as a function of the experimenter, all $X^{2} s(1, N=$ $80) \leq 1$. 93, $p s \geq .165, \varphi s \leq .15$, or as result of the lineup mode sequence, all $\chi^{2} s(3, N=$ $80) \leq 7.16, p s \geq .062$, Cramer $V s \leq .30$. Therefore, we will not discuss these factors any further.

Detection rates served at the dependent variable and were measured concurrently and retrospectively. Concurrent detection refers to detection immediately after the presentation of the manipulated outcome (e.g. 'I haven't chosen her. I believe the correct culprit in not among the photos', or 'I chose No 2 [i.e. original choice] because of her hair style.'). Retrospective detection additionally includes detection reported in the posttest questionnaire. That is, all concurrent detections are per definition also retrospective detections. Finally, based on the identification outcome, two additional dependent variables were calculated, namely lineup outcome (selection vs. rejection) and identification accuracy (accurate vs. inaccurate).

\section{Procedure}

Data collection took place at the campus of a European university. Participants were individually approached by one of the two male experimenters and were asked if they wanted to participate in a short study on face perception. This cover story was used to mask the real purpose of the study and to facilitate the controlled unfolding of a mock crime that took place while participants were engaged in a conversation with the experimenter. Upon agreement, participants signed a first informed consent form. At that point, the experimenter set down his backpack slightly behind him a few centimeters away from his standing point. Subsequently, the experimenter engaged participants in a conversation about their demographics. Meanwhile, the 'thief' approached the scene. While navigating herself around the experimenter and the participant, the thief kept track of the time on her cell phone so that she would be visible for $40 \mathrm{sec}$. After $40 \mathrm{sec}$ had elapsed, she grabbed the experimenter's (who from this point onward will be referred to as the victim) backpack and rushed into the university building. After initially acting confused 
(to allow the thief to get out of sight), the victim excused himself and hurried after the thief.

At that instant, participants were approached by the second experimenter who immediately revealed that the event had been staged and explained that the study was about eyewitness testimony. If consent to continue with the study was given, the victim and thief lineups were presented in succession. Participants were instructed that the target may or may not be present, were allowed to reject the lineup and were given unlimited time to make a decision. In order to introduce a short interval between the identification decision and the confrontation with this decision, participants were asked to provide a short written description of the event. Although no time limit was imposed for this task, participants took no more than a few minutes to complete their reports (note that the entire experiment lasted no more than $15 \mathrm{~min}$ ). Next, participants were presented with their two lineup decisions (i.e. with the identified lineup member or a question mark when the lineup had been rejected) and were asked to explain the reasons for their decision. Participants were always first presented with their victim lineup decision and then with the thief lineup decision. However, the decision made for the thief lineup was manipulated. Specifically, lineup member 1 was exchange with lineup member 2, member 3 with member 4, and member 5 with member 6 . In the case of a lineup rejection, participants were presented with the photo of the perpetrator when they had been presented with a TP lineup earlier and the photo of the replacement of the target when they had been presented with a TA lineup. This was done because these manipulations are the only ones that could result in a conviction. We refrained from manipulating both lineups (victim and thief). Rather we first confronted participants with their decision in the nonmanipulated lineup. This was to gain participants' trust and attention and to familiarize them with the lineup procedure (see Sagana et al., 2013 for a similar approach). Furthermore, we manipulated the thief lineup decision, rather than the victim lineup decision, as this decision is forensically most relevant. Finally, participants received the post-test questionnaire, were thanked and fully debriefed.

\section{Results}

\section{Blindness for identification decisions}

Across all 80 performed manipulations, concurrent blindness was $68.7 \%(n=55)$. Retrospectively, $55.0 \%(n=44)$ of the manipulations remained undetected. As expected, participants were less likely to be blind to manipulations from TA (concurrent: $M=55.0 \%, 95 \% \mathrm{Cl}$ $[39.8,69.3]$; retrospective: $M=42.5 \%, 95 \% \mathrm{Cl}[28.5,58.7])$ than from TP lineups (concurrent: $M=82.5 \%, 95 \% \mathrm{Cl}[68.1,93.1]$; retrospective: $M=67.5 \%, 95 \% \mathrm{Cl}[52.0,79.9])$, all $\chi^{2} \mathrm{~s}(1, N=$ $80) \geq 5.05, p s \leq .025, \varphi s \geq .25$, although the lineup outcome (selection vs. rejection) did not depend on target presence, $X^{2}(1, N=80)=1.86, p=.172, \varphi=.15$.

\section{The effect of the non-manipulated lineup on blindness rates}

Considering that the manipulated lineup was always presented second, we first tested whether the identification decision in the non-manipulated lineup affected blindness rates. Identification accuracy for the victim lineup was high $(M=72.5 \%, 95 \% \mathrm{Cl}$ [61.9, 
81.1]), and considerably lower for the thief $(M=42.5 \%, 95 \% \mathrm{Cl}[32.3,53.4]), \operatorname{McNemar} \chi^{2}(1$, $N=80)=12.02, p=.001$. The longer interaction time with the victim (i.e. the experimenter) compared with the thief may have been responsible for this difference, despite the central role of the thief in the crime scene. Consequently, we performed binary logistic regression analyzes with detection (detected vs. non-detected) as dependent variable, and lineup outcome (selection vs. rejection) and identification accuracy (accurate vs. inaccurate) of the non-manipulated victim lineup as predictors. Neither of the factors predicted blindness rates, all Wald $x^{2} s(1, N=80) \leq 0.75, p s \geq .388$. Therefore, for the remaining analyzes, we discuss result only for the thief lineup; that is the lineup where a manipulation was performed.

\section{Blindness as a function of lineup outcome}

In the current study, we were most interested in whether lineup outcome could determine participants' ability to detect our manipulations. To this end, we performed binary logistic regression analyzes with detection (detected vs. non-detected) as dependent variable, and lineup outcome (selection vs. rejection) as predictor. Analyses including target presence (present vs. absent) and the interaction effect of target presence and lineup outcome as additional predictors did not increase the variance explained by the model (concurrently: $82.5 \%$; retrospectively: $71.3 \%$ ). Therefore, we will only discuss the simpler model. The analysis returned a significant effect of lineup outcome for concurrent, Wald $X^{2}(1, N=80)=18.59, p<.001$, and retrospective detection, Wald $X^{2}(1, N=$ $80)=11.49, p=.001$. Figure 1 represents the mean concurrent and retrospective blindness rates as a function of lineup outcome. Inspection of the associated odds ratio showed manipulations involving selections to be 10 times less likely to be detected concurrently and 7.5 times less likely to be detected retrospectively than manipulations involving rejections. Thus, as expected, lineup selections were associated with higher blindness rates.

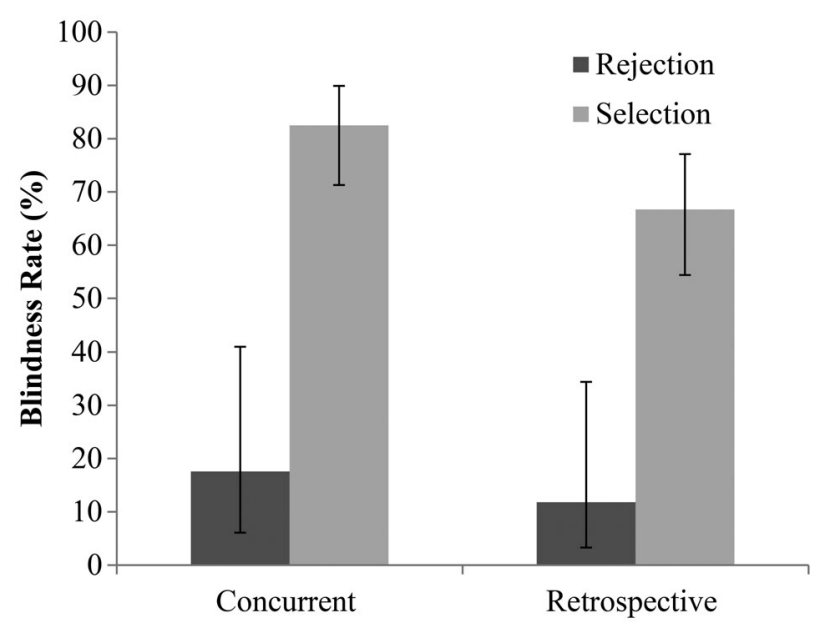

Figure 1 . Proportion of concurrent and retrospective detection as a function of lineup outcome (selection vs. rejection). Error bars represent $95 \%$ confidence intervals. 
One might argue that the difference in blindness rates for rejections vs. selections could be attributed to the fact that for selections, we performed manipulations both toward and away from the suspect as these different kinds of manipulations are different in nature. To address this concern, we performed the analysis again, this time including only those selections that involved a change toward the suspect. The results remained largely the same, with lineup outcome being a significant predictor of concurrent, Wald $\chi^{2}(1, N=$ $31)=9.73, p=.002$, and retrospective detection, Wald $\chi^{2}(1, N=31)=6.18, p=.013$. Manipulations of selections were 5.4 to 9.0 times less likely to be detected than those of rejections.

\section{Blindness as a function of identification accuracy}

Considering the vast differences in detection rates between selections and rejections, we examined the role of identification accuracy on detection separately for selections and rejections. The low number of blind participants $(n=3)$ among those who rejected the lineup ( $n=17)$ allows only a descriptive approach to the data. At a descriptive level, of the 11 participants who made a correct rejection 10 (90.9\%) detected the change both concurrently and retrospectively. Of the six participants who made an incorrect rejection, $4(66.7 \%)$ detected the change concurrently and 5 (83.3\%) did retrospectively. However, given the small number of the observations, we cannot draw conclusions about the effect of accuracy on blindness rates for lineup rejections. For selections, $x^{2}$ tests looking at detection rates as a function of identification accuracy revealed a significant effect of accuracy on concurrent, $X^{2}(1, N=63)=4.32, p=.044, \varphi=.26$, but not on retrospective detection, $X^{2}(1, N=63)=2.19, p=.193, \varphi=.19$. Specifically, participants who made an accurate selection from the thief lineup displayed higher blindness rates concurrently $(M=93.7 \%, 95 \% \mathrm{Cl}[86.6,100])$ than those who made an erroneous selection $(M=$ $75.0 \%, 95 \% \mathrm{Cl}[61.0,89.0])$.

\section{Discussion}

The present study aimed to investigate the effect of blindness for eyewitnesses' identification decisions under naturalistic encoding conditions. Above and beyond the replication of earlier findings indicating that blindness phenomena occur for eyewitness recognition decisions (Sagana et al., 2013, 2014b), the current study extended our knowledge by showing that blindness phenomena occur under conditions that come close to a real eyewitness setting. Importantly, our findings suggest that between-category changes are easier to detect than within-category changes in eyewitness identification decisions.

In particular, participants remained concurrently blind to our covert manipulations at a $68.7 \%$ rate and retrospectively at a $55.0 \%$ rate. Furthermore, our hypothesis that manipulations applied to rejections would be more likely to be detected compared with manipulations applied to selections was supported by the findings. In fact, rejection manipulations were approximately 7-10 times more likely to be detected than selection manipulations. Relatedly, blindness rates for manipulations of TA lineups were relatively low compared with those of TP ones. Clearly, the effect may ally with the higher number of nonchoosers in TA than in TP lineups (on a descriptive, but not statistically significant level). Finally, and in line with previous work looking into the role of memory in 
blindness phenomena (Sagana et al., 2014a, 2014b; Sauerland et al., 2014), poor identification accuracy was not a precondition for blindness. In fact, when identification accuracy influenced blindness, the effect was in the opposite of the expected direction. Indeed, for selections, blind participants were more accurate than detectors. This is a surprising finding pointing to the fact that, before we can formulate firm conclusions about the effect of accuracy on blindness, more conceptual replications of the present study are needed.

Consequently, it may be difficult to attain blindness for lineup rejections that are turned into identifications. Nevertheless, the reduced probability of blindness for manipulations applied to rejections should not be confused with a lack thereof. A non-trivial minority (12-18\%) of participants did accept having made a positive identification while they had in fact rejected the lineup. Thus, our findings do not imply that a rejection per se inoculates against blindness but they signal that the obviousness of the change is critical for the effect. We would expect a selection that is turned into a rejection to elicit comparable detection rates as a rejection that is turned into a positive identification. To conclude, the probability of noticing changes applied to one's identification decision is higher for higher order and thus more fundamental choice reversals compared with choice exchanges. Similarly, and despite the detection advantage of TA lineups, the low detection rates for both TA and TP lineups affirm that identification decision manipulations can affect the guilty as well as the innocent target.

From a theoretical stance, the increased detection rate for nonchoosers compared with choosers appears to be related to a greater attentional shift for the between-category than the within-category changes (Lyyra et al., 2014). This interpretation is consistent with the asymmetric features in choosers' and nonchoosers' identification decisions possess (Sauerland, Sagana, \& Sporer, 2012; Weber \& Brewer, 2004). Specifically, the eyewitness literature holds that while choosers base their identification decisions on the match between their memory of the culprit and one of the lineup members, nonchoosers' decisions seem to reflect a reluctance to identify any of the faces in the lineup as the culprit (Sporer et al., 1995; Weber \& Brewer, 2006). Therefore, when presented with a different lineup member, to detect changes choosers should focus their attention on the specific facial configuration of the manipulated face. Conversely, nonchoosers' attention should be more easily drawn to the fact that they are actually presented with a face while they should be presented with none. Hence, for nonchoosers, the subsequent presentation of a selection constitutes a distinct category conversion that is difficult to adopt as it directly contradicts their decision. From a theoretical point of view, turning a selection into a rejection should be an alteration equally difficult to accommodate as turning a rejection into a selection. That is because once a choice has been made, the witness is under the impression that at least one lineup member was a match. Hence, both types of manipulations (i.e. a rejection turned into a selection and vice versa) would constitute a between-category change. Although in the present study, we refrained from turning selections into rejections, a study testing this type of reversal may be beneficial for the theoretical understanding of blindness phenomena.

An alternative, yet related explanation for the increased detection of choice reversals comes from research on blindness for manipulations of self-reported symptoms (Merckelbach et al., 2011a, 2011b). Specifically, Merckelbach et al. reported that participants who 
were blind to manipulations of their psychological symptom ratings had initially scored higher both on the manipulated and the control symptoms compared with detectors. This indicates that participants who more frequently gave zero responses reflecting categorical decisions ('I don't have this symptom') were more likely to detect manipulations of their symptom ratings. Drawing from the misinformation literature (Loftus, 2005; Loftus \& Hoffman, 1989), Merckelbach et al. attributed the stronger tendency to blindness for nonzero responses to an increased ambiguity participants experienced compared with giving zero responses. That is, participants who gave non-zero responses may be more ambivalent as to which answer they provided than participants who categorically rejected the symptom as a whole. This in turn raises the probability of misinformation acceptance. Our findings are in line with this conceptualization because a lineup rejection can be viewed as an equivalent of a zero response.

Moving to the practical relevance of the present study, our findings imply that an innocent suspect might be at risk when a smooth manipulation takes place in a realworld investigation. Notably, the risk is greater in the presence of a foil identification rather than with a rejection. Although some might object to the idea of identification decisions being altered in real investigations, the Northern California Innocence Project report on prosecutorial misconduct cases sides with the idea (NCIP; Ridolfi \& Possley, 2010). The report reveals 4000 cases of alleged misconduct, in 707 of which the courts explicitly established that the prosecutors deliberately mishandled, mistreated or destroyed evidence. Against this background, our findings highlight the importance of double-blind identification administration that leaves little room for secret manipulations.

All in all, the current study extends the findings that blindness phenomena are relevant to eyewitness identifications by demonstrating that such phenomena can occur for choosers and, to a lesser extent, nonchoosers, as well as for TP and, to a lesser extent, TA lineups. Hence, identification decision manipulations could jeopardize the liberty of innocent suspects. Furthermore, our findings suggest that it is more difficult to convert a lineup rejection into an identification than to swap among identifications, which is good news for the judicial system. In sum, then, our findings contain important lessons for lineup administrators and law enforcement bodies. Certainly, future research is to determine the magnitude of blindness phenomena in real cases. Having said that, we believe that research on blindness phenomena is critical for the legal practice as it can provide useful insights into eyewitnesses' decision-making processes.

\section{Acknowledgements}

The authors acknowledge the strong support and valuable assistance of Rense Hoekstra in finding a study format that meets the research needs as well as the criteria of the standing ethical committee of our faculty. Finally, the authors would like to thank Sandra Sæbjörnsdóttir, Robin Sevenich and Stijn Valkenburg for their help in data collection.

\section{Disclosure statement}

No potential conflict of interest was reported by the authors. 


\section{Note}

1. A female experimenter with an Icelandic background acted always as the thief. This had to do with her limited capacity to interact with the participants in their native language (i.e., Dutch), which was a safety prerequisite imposed by the ethical committee.

\section{References}

Cutler, B. L., \& Penrod, S. D. (1995). Mistaken identification: The eyewitness, psychology and the law (1st ed.). Cambridge, NY: Cambridge University Press.

Hall, L., Johansson, P., \& Strandberg, T. (2012). Lifting the veil of morality: Choice blindness and attitude reversals on a self-transforming survey. PLOS ONE, 7, e45457. doi:10.1371/journal.pone. 0045457

Hall, L., Johansson, P., Tärning, B., Sikström, S., \& Deutgen, T. (2010). Magic at the marketplace: Choice blindness for the taste of jam and the smell of tea. Cognition, 117, 54-61. doi:10.1016/j.cognition. 2010.06.010

Johansson, P., Hall, L., \& Sikström, S. (2008). From change blindness to choice blindness. Psychologia: An International Journal of Psychology in the Orient, 51, 142-155. doi:10.2117/psysoc.2008.142

Johansson, P., Hall, L., Sikström, S., \& Olsson, A. (2005). Failure to detect mismatches between intention and outcome in a simple decision task. Science, 310, 116-119. doi:10.1126/science.1111709

Loftus, E. F. (2005). Planting misinformation in the human mind: A 30-year investigation of the malleability of memory. Learning \& Memory, 12, 361-366. doi:10.1101/Im.94705

Loftus, E. F., \& Hoffman, H. G. (1989). Misinformation and memory: The creation of new memories. Journal of Experimental Psychology: General, 118, 100-104. doi:10.1037/0096-3445.118.1.100

Lyyra, P., Mäkelä, H., Hietanen, J. K., \& Astikainen, P. (2014). Implicit binding of facial features during change blindness. PLOS ONE, 9, e87682. doi:10.1371/journal.pone.0087682

McLaughlin, O., \& Somerville, J. (2013). Choice blindness in financial decision making. Judgment and Decision Making, 8, 561-572.

Merckelbach, H., Jelicic, M., \& Pieters, M. (2011a). Misinformation increases symptom reporting - a test-retest experiment. Journal of the Royal Society of Medicine Short Reports, 2, 75. doi:10.1258/ shorts.2011.011062

Merckelbach, H., Jelicic, M., \& Pieters, M. (2011b). The residual effect of feigning: How intentional faking may evolve into a less conscious form of symptom reporting. Journal of Clinical and Experimental Neuropsychology, 33, 131-139. doi:10.1080/13803395.2010.495055

Ridolfi, K., \& Possley, M. (2010). Preventable error: A report on prosecutorial misconduct in California 1997-2009. Santa Clara, CA: Northern California Innocence Project.

Sagana, A., Sauerland, M., \& Merckelbach, H. (2013). Witnesses' blindness for their own facial recognition decisions: A field study. Behavioral Sciences \& the Law, 31, 624-636. doi:10.1002/bsl.2082

Sagana, A., Sauerland, M., \& Merckelbach, H. (2014a). Memory impairment is not sufficient for choice blindness to occur. Frontiers in Psychology, 5, 449. doi:10.3389/fpsyg.2014.00449

Sagana, A., Sauerland, M., \& Merckelbach, H. (2014b). 'This is the person you selected': Eyewitnesses' blindness for their own facial recognition decisions. Applied Cognitive Psychology, 28, 753-764. doi:10.1002/acp.3062

Sauerland, M., Sagana, A., \& Otgaar, H. (2013). Theoretical and legal issues related to choice blindness for voices. Legal and Criminological Psychology, 18, 371-381. doi:10.1111/j.2044-8333.2012.02049.x

Sauerland, M., Sagana, A., Otgaar, H., \& Broers, N. J. (2014). Self-relevance does not moderate choice blindness in adolescents and children. PLOS ONE, 9, e98563. doi:10.1371/journal.pone.0098563

Sauerland, M., Sagana, A., \& Sporer, S. L. (2012). Assessing nonchoosers' eyewitness identification accuracy from photographic showups by using confidence and response times.. Law and Human Behavior, 36, 394-403. doi:10.1037/h0093926

Sauerland, M., Schell, J., Collaris, J., Reimer, N., Schneider, M., \& Merckelbach, H. (2013). "Yes, I have sometimes stolen bikes": Blindness for norm-violating behaviors and implications for suspect interrogations. Behavioral Sciences and the Law, 31, 239-255. doi:10.1002/bsl.2063 
Sauerland, M., Schell-Leugers, J. M., \& Sagana, A. (2015). Fabrication puts suspects at risk: Blindness to changes in transgression-related statements. Applied Cognitive Psychology, 29, 544-551. doi:10. 1002/acp.3133

Sporer, S. L., Penrod, S., Read, D., \& Cutler, B. (1995). Choosing, confidence, and accuracy: A metaanalysis of the confidence-accuracy relation in eyewitness identification studies. Psychological Bulletin, 118, 315-327. doi:10.1037/0033-2909.118.3.315

Steenfeldt-Kristensen, C., \& Thornton, I. M. (2013). Haptic choice blindness. i-Perception, 4, 207-210. doi:10.1068/i0581sas

Tredoux, C. G. (1998). Statistical inference on measures of lineup fairness. Law and Human Behavior, 22, 217-237. doi:10.1023/A:1025746220886

Tredoux, C. G. (1999). Statistical considerations when determining measures of lineup size and lineup bias. Applied Cognitive Psychology, 13, S9-S26. doi:10.1002/(SICI)1099-0720

Weber, N., \& Brewer, N. (2004). Confidence-accuracy calibration in absolute and relative face recognition judgments. Journal of Experimental Psychology: Applied, 10, 156-172. doi:10.1037/1076898X.10.3.156

Weber, N., \& Brewer, N. (2006). Positive versus negative face recognition decisions: Confidence, accuracy, and response latency. Applied Cognitive Psychology, 20, 17-31. doi:10.1002/acp.1166

Wells, G. L., Small, M., Penrod, S., Malpass, R. S., Fulero, S. M., \& Brimacombe, C. A. E. (1998). Eyewitness identification procedures: Recommendations for lineups and photospreads. Law and Human Behavior, 22, 603-647. doi:10.1023/A:1025750605807

Wolchover, D. (n.d.). Visual identification procedures under PACA code D. Retrieved from http://www. davidwolchover.co.uk/docs/Visual\%20ldentification\%20Procedures.doc 